\title{
Taxation and Citizen Voice in School District Parcel Tax Elections
}

\author{
Isaac William Martin, ${ }^{a}$ Jennifer M. Nations ${ }^{\mathrm{b}}$
}

a) University of California, San Diego; b) Scholars Strategy Network

Abstract: Local taxation produces consequential resource inequalities among public school districts, but little is known about how policy design affects taxpayers' willingness to pay for schooling. We show that voters are more likely to approve local school taxes if the policy is written to require citizen-state consultation on how the funds are spent. In a sample of 236 California school district elections, the promise of indirect consultation with a citizen advisory board was associated with a 3.7 percentage-point greater share of voters and a probability of passage that was 31 percentage points greater, whereas direct consultation with voters was associated with a 5.7 percentage-point greater share of voters and a probability of passage that was 32 percentage points greater, relative to a proposed tax increase with no consultation. These results provide evidence that citizens may trade increased taxation for increased voice even within an established democracy.

Keywords: taxation; fiscal sociology; democracy; school finance

Citation: Martin, Isaac W., and Jennifer M. Nations. 2018. "Taxation and Citizen Voice in School District Parcel Tax Elections." Sociological Science 5: 653-668.

Received: August 2, 2018

Accepted: September 24, 2018

Published: October 29, 2018

Editor(s): Jesper Sørensen, Delia Baldassarri

DOI: $10.15195 /$ v5.a27

Copyright: (C) 2018 The Author(s). This open-access article has been published under a Creative Commons Attribution License, which allows unrestricted use, distribution and reproduction, in any form, as long as the original author and source have been credited. (C) (i)
RE citizens willing to pay more for public schools in exchange for a greater voice in how the money is spent? Recent studies by economists and sociologists conclude that resource differences among public school districts can yield unequal learning outcomes (Jackson, Johnson, and Persico 2016; Lafortune, Rothstein, and Schanzenbach 2018; Owens 2018). Most of the resources available to public schools come from taxation, but sociologists still know relatively little about which institutional designs may make taxpayers more or less willing to pay for public schools. We test a hypothesis derived from political sociology: that the public's willingness to pay for public schools depends, in part, on whether school taxes are coupled with institutional arrangements for citizen voice. Political sociologists have long argued that citizens may demand to be consulted as the price of their acquiescence to taxation (Schumpeter [1918] 1991; Tilly 2009). This argument was first used to explain the emergence of aristocratic parliaments in early-modern Europe. It was subsequently generalized into a "fiscal theory of democracy" (Ross 2012) that was applied to explain the spread of such modern democratic institutions as competitive elections and equal suffrage. We propose, and test, a further generalization: Even within an established democracy, voters may be most amenable to increased taxes if the demand for revenue is accompanied by procedural concessions. In particular, voters may be most likely to concede additional resources if officials commit to consult with citizens on how those resources are spent.

We test this hypothesis with a new database of school district parcel tax proposals presented to California voters over the period from 1997 through 2010. Our sample includes local elections in which voters in a given school district were asked explicitly to affirm their willingness to be taxed at a given rate. Within this sample, the structure of the proposed tax (a levy on owners of real estate, assessed at a fixed 
dollar amount per parcel) and its general purpose (spending on public schools) are held constant. The proposals varied, however, in whether and how they coupled the tax with institutional mechanisms for consultation. Almost half of the proposals we analyze (43 percent) paired a tax increase with a promise of what we describe as indirect consultation in the form of a citizens' oversight committee charged with reviewing how the revenues were spent. Proposals also varied in whether, and with what frequency, they promised what we describe as direct consultation in the form of a commitment to return to the voters for reauthorization. We characterize such procedural arrangements with Tilly's (2009:181) concept of "citizen-state consultation," in preference to the terms "democracy" or "representation," because we do not wish to prejudge whether, as a matter of normative political theory, these forms of consultation should be regarded as truly democratic or representative. Our purpose in this article is to assess whether citizens do, in fact, trade increased taxes for increased consultation rather than to assess the quality of that consultation.

We fit fixed effects and correlated random effects regression models to identify the average within-district differences in the percentage of voters who supported tax proposals depending on whether those proposals institutionalized either form of consultation. We find evidence that voters in the same school district were more likely to accept increased taxation if it was coupled with consultation. When a tax increase was coupled with indirect consultation, an additional 3.7 percent of voters were expected to approve it compared with a similar measure in the same school district without any promise of consultation. When a tax increase was coupled with direct consultation, an additional 5.7 percent of voters were expected to approve it relative to a tax increase without a promise of consultation. These differences may appear modest, but they were often sufficient to swing close elections. We find that a measure with either form of consultation was more likely to pass than a comparable measure, proposed to voters of the same district, that did not include any promise of consultation, and the difference in the likelihood of passage could be 30 percentage points or more.

This study provides new evidence that taxpayers' support for public schooling may vary with institutional design for state-citizen consultation. It also provides new observational evidence of a behavioral mechanism - an explicit exchange of increased taxation for increased voice- that has been assumed, but rarely measured, in the political sociology of democratization. These findings are consistent with the hypothesis that voters demand accountability in exchange for taxes but that a variety of different institutional designs may satisfy citizen demands for accountabilityand therefore that the fiscal theory of democratization may have more general application than has been appreciated.

\section{Taxation and Consultation}

An influential argument in political sociology holds that state officials' demands for increased taxation typically produce public demands for accountability. As Tilly (2009) glossed the argument, a state that would extract resources from its subjects must bargain for the consent of those subjects; as early-modern rulers approached their subjects for resources with increasing frequency, such bargaining 
came to be routinized, and the resulting processes of consultation yielded many of the institutional innovations that we now associate with representative democracy. Schumpeter (1991 [1918]), in his classic essay on "fiscal sociology," offered a version of this argument to account for the convening of the estates by the Habsburg monarchy; Tilly (2009:179) asserted that the same theory could account for "most of the world's democratization over the last 200 years," and its influence has been such that Paler (2013:706), writing in the American Journal of Political Science, called it "almost a truism in political science" that citizens bargain for representation as the price of their consent to be taxed.

But should citizens in an established democracy be expected to demand increased consultation in exchange for increased taxes? Prior studies are inconclusive. The fiscal theory of democratization is associated with a very general argument that taxation increases "citizen motivation to hold government accountable" (Paler 2013:707), but abstract statements of the theory provide little guidance about precisely how much consultation should be expected to satisfy demands for accountability. Scholars have typically tested the theory with data on the emergence of the first representative institutions in previously authoritarian settings (Ross 2004; Boucoyannis 2015; Møller 2017). Such studies provide evidence that taxation can lead to effective demands for at least some minimal degree of electoral representation, but they do little to clarify whether or how state officials' subsequent demands for increased taxation might relate to citizens' demands for increased consultation above the barest minimum. Although the fiscal theory of democratization also has been invoked to explain the emergence of such varied political institutions as aristocratic parliaments, municipal corporatism (Bates and Lien 1985), equal suffrage, and the popular referendum, among others (Martin 2015), abstract statements of the theory are often vague with respect to precisely which institutional arrangements satisfy citizen demands for accountability.

The hypothesized bargain-in which taxpayers acquiesce to increased taxation in exchange for institutionalized consultation-is also difficult to measure because consent to taxation is difficult to observe directly. In rare historical upheavals, revolutionaries may assert that "taxation without representation is tyranny" or write new constitutions that explicitly balance the power to tax with rights of representation. But events such as the American Revolution, in which republicans explicitly contest the power to tax and design new governmental institutions, are uncommon. Scholars who have attempted to test the fiscal theory of democratization with a sufficient sample size for statistical inference have been forced to infer the existence of the hypothesized bargain indirectly from cross-national correlations between aggregate tax revenues and aggregate indices of democracy (Ross 2004; Baskaran and Bigsten 2013; Gur 2014), which provide little insight into which particular policy decisions may have been traded for which institutional arrangements. Other scholars have used survey instruments or experimental games to understand the presumptive taxation-for-accountability bargain, but the relevance of such studies to behavior outside of the experimental setting is unknown (Paler 2013). The literature contains few examples in which a taxation-for-accountability bargain is struck explicitly, with the result being that some scholars doubt that "bargaining" describes the relevant historical process at all (Boucoyannis 2015). 
We overcome this problem with a study of 236 local elections in which voters were asked explicitly to affirm their willingness to be taxed at a given rate. Our sample of tax proposals is limited to parcel tax measures put before voters by California school districts. Within this sample, the structure of the tax and its general purpose are held constant. The proposals varied, however, in whether and how they would institutionalize future consultation over the use of tax revenues.

California's tax regime provides an especially rich context for studying the fiscal bargaining process between public officials and citizens. A 1978 amendment to the state constitution (Proposition 13) required all local tax increases to be submitted to the voters for approval, and-as subsequently interpreted by the courts-required a two-thirds majority of the voters of a school district to approve any local tax earmarked for public schools. Subsequent developments in state law, culminating in a 1996 constitutional amendment (Proposition 218), standardized the requirements for such elections and foreclosed many alternative revenue strategies for public schools. This legal framework effectively left the state's local school boards with one way to increase taxes: asking the voters to approve a parcel tax, which is a lump-sum tax per parcel of real property (in contrast to a property tax, which is levied on the value of real property). School district parcel tax measures often enumerate specific purposes for which revenues will be spent and specify institutional mechanisms for consultation with citizens to ensure that the revenues are spent as promised. The state averages more than 20 such measures per year. The record of parcel tax elections since 1997 therefore provides an ample documentary record of how voters responded to proposals that explicitly coupled increased taxation and increased consultation.

We hypothesize that both direct and indirect consultation will be associated with greater support for a tax increase net of other considerations, including the size of the tax, the demographics of the district's student population, and the district's budget. Other things being equal, tax measures that promise any form of consultation will be approved by a greater share of voters, and will be more likely to pass, than tax measures that do not.

\section{Data and Method}

We rely on a new data set of school district parcel tax measures that includes nearly every parcel tax proposed to residents in any California school district. For the present analysis, we limit the sample to years between 1997 and 2010 because the legal regime governing this type of tax was homogenous during this period. The California Elections Data Archive (CEDA) and the California Debt and Investment Advisory Commission (CDIAC) published lists of measures and election results, which we used to identify school districts for which parcel taxes appeared on the ballot and districts where they were approved by voters. We excluded school bond measures, which are regulated differently from other tax measures and involve calculations of future debt obligations that may elicit different voter behavior. A team of research assistants collected local government documents describing these parcel tax measures, including sample ballots, voter information guides, and school 
district resolutions. The archive containing these primary source documents is available online (Martin, Lopez, and Olsen 2017).

Coding the measures was a deductive exercise. We drew on prior research in fiscal sociology and behavioral public finance to identify potentially salient dimensions of tax policy that might influence voter behavior. Research assistants coded measures for information about the magnitude of the tax, exemptions, sunset provisions, and citizen oversight provisions.

The analyses reported below include 236 parcel tax measures in 83 separate districts. The measures include proposals to enact a new parcel tax, increase the rate of parcel taxation, and authorize the continuation of a previously enacted parcel tax. In order to construct a meaningful within-district estimator, we limit the sample to those districts that considered parcel taxes more than once. Because of this limitation, our sample of 83 districts represents a small fraction of California's more than 900 public school districts. The districts in the resulting sample had, on average, less intergovernmental revenue per capita than the average California school district and greater annual budget shortfalls, both of which are consistent with the assumption that officials in these school districts may have been especially motivated to propose local tax increases. The districts in our sample also had fewer Hispanic students than the average California school district, which is consistent with the assumption that their voters might have been especially willing to support increased public spending on schools; sociologists have found that voters in at least some majority-white jurisdictions are less willing to support tax increases when they believe the results will be spent to benefit Latino residents ( $\mathrm{O}^{\prime}$ Brien 2017). In other respects, the sample appears unremarkable. The ballot measures included in our sample received 70 percent of the vote, on average, and were approved about 67 percent of the time. More descriptive information about the characteristics of this sample in comparison with the population of California school districts can be found in the online supplement.

We fit linear models that relate the share of voters who approve a tax $(\mathrm{Y})$ to a vector of policy design features $(X)$ and contextual features of the school district $(Z)$. Policy features that affect the share of affirmative votes on average, however, may differ from those that most affect the likelihood that a policy will pass: The twothirds supermajority requirement to enact a school district parcel tax means that the pivotal voter who casts the decisive vote may be different from, and more tax averse than, the median voter. For this reason, we also fit linear probability models in which the dependent variable $\mathrm{Y}$ is a dichotomy equal to one if the proposed measure passed and equal to zero if it failed. The latter strategy may be understood to model which policy design features were particularly associated with the support of the pivotal voter at the two-thirds threshold required for passage.

Our focal independent variables in $\mathrm{X}$ include measures of indirect and direct consultation. To capture indirect consultation, we coded each proposed measure for whether the ballot question made explicit provision for a citizen committee specifically charged with oversight of the expenditure of funds from the tax. Coders were instructed as follows: "Some measures include the mandatory establishment of a citizen oversight committee to supervise the expenditure of funds collected through the tax. Does this measure include a provision to create a citizen oversight 
committee?" The coding of this variable may be illustrated by comparing two ballot questions put before the voters of the Santee Unified School District in San Diego: Measure J (March 2, 2004) and Measure Y (November 2, 2004). The text of both ballot questions was substantially identical but for the additions, italicized below, that appeared only in Measure Y:

...shall Santee School District be authorized to levy and collect an annual special assessment for five years only, beginning July 1, [year], at the rate of $\$ 60$ per year for each residential parcel within the school district and $\$ 400$ per year for each commercial, industrial, or nonresidential use parcel within the School District with an exemption for any parcel whose beneficial owner has attained the age of 65 on or before July 1 of any assessment year and who uses that parcel as his or her principal place of residence, with no proceeds going to the state or administrator salaries, with all funds staying in Santee to benefit local schools, with annual oversight of funds by a citizens' committee and annual audits, and shall the Santee School District implement accountability measures in connection with the special assessment?

We coded Measure $Y$ as requiring a citizens' oversight committee and Measure J as requiring none.

To measure the frequency of direct consultation, coders were instructed to record whether voter approval of a proposed tax increase was scheduled to expire (or "sunset") after a specified period of time and, if so, to record the number of years from the election until the scheduled date of expiry. A tax increase that sunsets requires voters' reauthorization. For the purposes of this analysis, we created a binary variable equal to one if the proposed tax was scheduled to expire in five years or sooner and another binary variable equal to one if a proposed tax measure was scheduled to expire after a period of six years or longer. A proposed tax increase that is scheduled to sunset within five years is assumed to imply more frequent direct consultation.

We control for three additional features of the policy proposal that may have bearing on voters' willingness to approve it. First, we control for the proposed rate of tax expressed in the natural logarithm of dollars per residential parcel. Assuming the median voter to be a homeowner who does not own a business or a second home, this is the tax increase faced by the median voter. We hypothesize that voters were more likely to reject more expensive taxes. Second, we control for whether the proposed parcel tax includes an exemption for the elderly. Some previous research on public support for school finance indicates that elderly voters, who typically do not have school-age children and who may be especially concerned about the effects of a parcel tax on their fixed incomes, may be more likely to oppose school tax increases (Tedin, Matland, and Weiher 2001; Plutzer and Berkman 2005). Perhaps for this reason, 86 percent of the parcel tax proposals in our sample were drafted specifically to exempt elderly people or elderly homeowners in particular. We control for a dichotomous measure of the presence of any policy language exempting elderly people or elderly homeowners because we hypothesize that it might correlate with voters' support for the measures. Third, we control for the 
timing of the tax increase in relation to the election. Previous research has shown that voters may be substantially more likely to approve of a tax increase if they are consulted after implementation than if they are consulted beforehand (Pearson 2014; Martin, Lopez, and Olson 2018). We anticipate a similar finding for district parcel taxes: Proposals to continue a previously implemented tax increase are expected to win greater approval than proposals to implement a tax increase in the future.

Our models also adjust for several contextual factors that could account for voters' support for local school funding. We control for the percentages of enrolled students in the district who were identified as black and Hispanic, respectively, in annual reports to the California Department of Education. We also control for the natural logarithm of the school district's intergovernmental revenue per capita as a proxy for the availability of other school district revenues. This measure comes from the quinquennial Census of Governments and is imputed linearly to intercensal years. Finally, we include a measure of the homeownership rate, or the proportion of district-resident households that were owner occupied, computed from decennial census data and linearly imputed to intercensal years. There is some evidence that homeowners may be particularly averse to property taxes (Ladd and Wilson 1983; Sears and Citrin 1985), and we might expect them to be more likely to vote against parcel taxes.

The principle threat to the validity of our inferences is the possibility that both the design of a policy and the decision to place it on the ballot may be endogenous to voters' likelihood of approving it. The decision to place a parcel tax measure on the ballot is not random. It is likely that school district officials who wish to raise revenues may anticipate the outcome before they go to the trouble and expense of calling an election on a particular proposal. The existence of an industry of consultants who conduct polls on the wording of ballot questions in order to advise school districts on policy design (Scott 2013) is prima facie evidence that policy design may be endogenous to the degree of voter support or the likelihood of passage. Observed differences in support between proposals with and without provisions for indirect consultation, for example, might simply tell us that school boards only promised such consultation in cases in which they already knew voters would support increased school district funding.

Our strategy for addressing the possible bias induced by endogenous sample selection has two parts. First, we address the possibility that unobserved, timeconstant factors may predispose the school districts in our sample to both put tax measures on the ballot and approve them. It is reasonable to assume that some school districts' voters are simply more likely than other school districts' voters to favor increased taxation for schools. We adjust for unobserved, time-invariant differences among school districts with a correlated random effects (CRE) estimator. This estimator goes under various names; our choice of terminology is due to Wooldridge (2002). We fit the following equation to our data, in which subscript $i$ represents unique districts, $t$ denotes years, and $k$ represents policy proposals:

$$
Y_{k i t}=\alpha+\beta^{\prime}\left(X_{k i t}-\bar{X}_{i}\right)+\gamma^{\prime}\left(Z_{i t}-\bar{Z}_{i}\right)+\xi^{\prime} \bar{X}_{i}+\zeta^{\prime} \bar{Z}_{i}+\eta \hat{\lambda}_{i t}+\delta_{t}+\varepsilon_{k i t} .
$$


Here, $\mathrm{Y}$ is the dependent variable: In Model 1, it is the percentage of voters approving the measure, and in Models 2 and 3, it is a binary indicator equal to one if the measure passed. The vector $\beta$ includes the coefficients of the within-district components of our measures of policy characteristics, including the measures of consultation that are of focal interest for our analysis. The vector $\gamma$ includes coefficients of the within-district components of contextual covariates that describe the school district, and $\xi$ and $\zeta$ represent coefficients of between-district components. The symbol $\delta$ represents a vector of dummy variables for year, and $\varepsilon$ is a stochastic error term. We decompose any district-specific, time-invariant correlates of $Y$ into a linear combination of district-averaged variables $\bar{X}_{i}$ and $\bar{Z}_{i}$ and a residual that is independent of $X$ and $Z$ by construction (Mundlak 1978). This permits us to interpret $\beta$ as equivalent to a fixed-effects (FE) estimator. Perhaps the most commonly cited advantage of CRE over the common FE estimator is that CRE allows for explicit measurement of coefficients of time-invariant characteristics of the observational units (school districts, in our case; Fairbrother 2014; Bell and Jones 2015). For our purposes, however, the coefficients $\xi$ and $\zeta$ are not of substantive interest, and it is another advantage of CRE that is more important: It permits adjustments for time-varying sample selection bias. We compute $\bar{Z}_{i}$ for all years from 1997 to 2010, including those during which no tax measures were on the ballot, so that we can interpret $\beta$ as an estimator that has not been distorted by endogenous sample selection correlated with Z (Wooldridge 1995; Semykina and Wooldridge 2010).

The second part of our strategy is to treat the decision to place a tax measure on the ballot as a process to be modeled explicitly. In particular, we include a predicted nonselection hazard $\hat{\lambda}_{i t}$ in our models. This strategy requires us to identify the population of potential measures and construct a model of the likelihood that a measure will appear on the ballot (following the well-known Heckman twostep estimator; see Semykina and Wooldridge 2010 for an introduction to this approach in the context of CRE models). We assumed that the population of potential measures was equivalent to the set of actual measures plus one possible measure for each school-district year during which no measure appeared on the ballot. We estimated the nonselection hazard $\lambda_{i t}$ for each district-year as one minus the predicted probability computed from a probit model whose dependent variable was the presence of a tax measure on the ballot. For each year from 1997 to 2010, we fit a separate cross-sectional probit model to data on our population of potential measures, including annual observations of 916 California school districts that were observed for all or part of the period. Each probit model expressed the probability of observing a ballot measure as a cumulative standard normal function of a vector of covariates $\mathrm{W}$, defined as a superset of $\mathrm{Z}$ that included two additional predictors. The first additional predictor was the inverse hyperbolic sine of the budget shortfall, measured as the difference between the total expenditures and total revenues reported by the district in the Census of Governments. We interpolated intercensal values linearly. A district experiencing a substantial budget shortfall might be especially likely to ask the voters to approve a new tax. The second additional predictor was the annual reported total enrollment in the school district. School districts with more students might be expected to face more resource demands and therefore be more likely to propose a tax increase. We decomposed $\mathrm{W}$ into 
longitudinal and cross-sectional components so that our model of the nonselection hazard is represented as follows:

$$
P\left(Y_{k i t} \text { observed } \mid W_{i t}\right)=1-\lambda_{i t}=\Phi\left(\kappa_{t}+v_{t}^{\prime}\left(W_{i t}-\bar{W}_{i}\right)+v_{t}^{\prime} \bar{W}_{i}\right),
$$

where $\Phi$ is the cumulative standard normal distribution function, $\kappa$ is a constant, and $v$ and $v$ are vectors of coefficients for the cross-sectional and longitudinal components of $W$, respectively. Repeated cross-sectional estimation, instead of pooled cross-section time series, permits the coefficients in $v$ to vary by year and permits asymptotically unbiased parameter estimation (Semykina and Wooldridge 2010). The McKelvey and Zavoina pseudo- $R^{2}$ statistics for the probit selection equations varied from 41 percent to 90 percent with an average of 61 percent. The model coefficients are summarized in the online supplement. We use these regression equations to compute a predicted value of $\lambda_{i t}$ for each observed measure; we represent this predicted value as $\hat{\lambda}_{i t}$.

Our two-step estimator (by means of which we estimate $\lambda_{i t}$ first, and only then $\beta$ ) will yield asymptotically unbiased estimates of $\beta$ on the strong assumption that we have modeled sample selection correctly. In a finite sample, in which the true selection process is not known with certainty, as Stolzenberg and Relles (1990) have shown, explicit estimators of sample selection such as this one sometimes perform poorly. We therefore also report coefficient estimates from FE models without any explicit model of the nonselection hazard. These models have the following form:

$$
Y_{k i t}=\alpha+\beta^{\prime} X_{k i t}+\gamma^{\prime} Z_{i t}+\delta_{t}+\omega_{i}+\varepsilon_{k i t} .
$$

In this equation, subscript $i$ represents unique districts, $t$ denotes years, and $k$ represents policy proposals. The dependent variable (the percentage of voters approving a measure, or a dichotomous indicator of passage, respectively) is represented by Y. The vector $\beta$ includes the variables of interest in our model, or the coefficients of the within-district components. The $\gamma$ vector includes the coefficients of contextual variables. The term $\delta$ represents a vector of dummy variables for year, $\omega$ represents a vector of implicit district-specific intercepts assumed to be fixed, and $\varepsilon$ is a stochastic error term. The FE models do not require the assumption that we have modeled the sample selection process correctly, but they impose the different, and arguably equally strong, assumption that the sample selection is ignorable.

In the following section, we report coefficients from both CRE and FE models. The estimators produce nearly identical coefficients for the focal variables, suggesting that our conclusions are robust to this choice of modeling strategy. (In supplemental models, we also tested a conditional random effects logit specification for our models of policy passage; our qualitative findings remained unchanged, and we report coefficients from linear probability models for ease of interpretation.)

\section{Findings}

Do promises of future consultation improve the likelihood that voters will approve of school district tax increases? Below, we present averages for the share of voters 
approving a measure, and the share of measures that passed, by whether or not the measures included provisions for fiscal consultation.

We begin with indirect consultation measured by the inclusion of a provision for a citizens' advisory committee. A simple comparison of averages suggests very little difference between the share of votes cast for proposals that included, and those that omitted, indirect consultation. The first column of Table 1 shows that the average share of yes votes was about 70 percent when measures proposed indirect consultation and about 70 percent when they did not. The second column shows that the rate of passage was greater by about 3 percentage points for measures that included provisions for indirect consultation compared with measures that did not. This difference is in the hypothesized direction, but it is small, and its magnitude is exceeded by its standard error. These raw differences are inconclusive; they are unadjusted for other characteristics of the proposed tax and the district, and they may confound variation across policy proposals with variation across districts that have very different propensities to favor increased taxation for schools.

The last two lines of Table 1 present adjusted differences computed from our within-district estimators. These represent the average differences within the same district in support for tax proposals with and without a provision for indirect consultation. These differences are adjusted for common temporal variation, other policy characteristics (including the rate of tax), and contextual characteristics of the district. Our CRE model, which includes an explicit adjustment for sample selection, indicates that a proposal that coupled a tax increase with indirect consultation would be expected to receive a 3.7 percentage point greater share of affirmative votes compared with another proposed tax increase in the same district that did not provide for consultation. The FE estimator, which omits explicit sample selection adjustment, yields a virtually identical estimate of 3.6 percentage points. Both estimates are statistically suggestive $(p<0.05$; our terminology here follows Benjamin et al. 2017).

Even 3.7 percent of voters may be influential if they include the pivotal voter at the two-thirds threshold required for passage, and the evidence is consistent with the hypothesis that indirect consultation made a big difference for the probability that a tax measure would pass. The second column of Table 1 reports our estimates of the adjusted differences in the probability of passage associated with indirect consultation. Here, the CRE model implies that if voters of a district were presented with two otherwise identical parcel tax measures, the one that provided for indirect consultation would have had a 31 percentage point greater expected probability of passage. This difference is statistically significant $(p<0.005)$. School boards may have been especially likely to promise indirect consultation when there was a high probability that such a promise would provide the margin of victory.

We turn now to direct consultation as measured by the frequency with which a school board must return to the voters for approval to continue the proposed tax. Table 2 reports the mean share of votes for measures depending on the frequency of direct consultation. As with indirect consultation, the comparison of raw averages is inconclusive. The average share of voters is similar for measures that do and do not couple parcel tax increases with consultation and varies little with the frequency 
Table 1: Share of yes votes and passage as a function of indirect consultation in ballot measures for California school district parcel taxes, 1997-2010.

\begin{tabular}{lcc}
\hline & (1) Vote share & (2) Probability of passage \\
\hline With indirect consultation & $69.7(0.7)$ & $0.68(0.05)$ \\
Without indirect consultation & $70.2(0.7)$ & $0.65(0.04)$ \\
Raw difference & $-0.4(1.0)$ & $0.03(0.06)$ \\
Within-district difference & & \\
$\quad$ From CRE model with sample selection adjustment & $3.7^{\dagger}(1.4)$ & $0.31^{*}(0.09)$ \\
$\quad$ From FE model & $3.6^{\dagger}(1.3)$ & $0.30^{*}(0.09)$ \\
\hline
\end{tabular}

Standard errors are in parentheses.

${ }^{*} p<0.05,{ }^{+} p<0.005$

of consultation. The rate of passage was lowest for measures that required no direct consultation, though the difference is slight.

The within-district estimators adjust these differences for characteristics of districts and measures. This adjusted comparison shows that a tax increase that required voter reauthorization within five years-which we characterize as frequent direct consultation - was associated with a share of affirmative votes that was almost 6 percentage points greater than a measure with no such sunset provision. The difference is statistically significant $(p<0.005)$. Direct consultation, like indirect consultation, appears to have had a greater effect on the likelihood of passage than on the share of the voters approving the measure. The CRE model implies that if voters of a district were presented with two otherwise identical parcel tax increases, one of which was scheduled to expire within five years unless voters approved it again and the other of which had no expiration date, the proposal requiring frequent direct consultation would be 32 percentage points $(p<0.05)$ more likely to pass. As might be expected, infrequent consultation was associated with levels of support between the levels associated with frequent consultation and the levels associated with no consultation, but these differences are not estimated with much certainty.

Because our inferences rest on within-district comparisons over time, one possible threat to our inferences is the possibility that the correlations between forms of consultation and voter approval are artifacts of temporal sequence. For example, as we have noted, public officials in the Santee Unified School District first introduced Measure J in 2004, which did not provide for indirect consultation, and only after it failed introduced Measure $Y$, an otherwise identical measure with a provision for indirect consultation; if voters' preferences changed during the intervening period for unrelated reasons-perhaps it simply takes multiple elections for voters to grow habituated to the idea of raising taxes-then our model specification might lead us to mistake the mere effect of maturing voter preferences for an effect of policy design. We inspected the data and found little evidence that policy design varied systematically with the position of the policy in a sequence. We found that school districts in our sample became more likely to promise indirect consultation after their first parcel tax measure, although the difference was not statistically significant (45 percent of measures that promised indirect consultation, and 52 percent of those 
Table 2: Share of yes votes and passage as a function of direct consultation in ballot measures for California school district parcel taxes, 1997-2010.

\begin{tabular}{lcc}
\hline & (1) Vote share & (2) Probability of passage \\
\hline Requiring frequent consultation, defined as within 5 years & $69.8(0.8)$ & $0.64(0.05)$ \\
Requiring infrequent consultation, defined as every 6 years or less often & $70.1(0.7)$ & $0.69(0.04)$ \\
Requiring no consultation & $69.9(1.4)$ & $0.63(0.09)$ \\
Raw difference, frequent consultation vs. none & $-0.1(1.6)$ & $0.01(0.10)$ \\
Within-district difference, frequent consultation vs. none & $5.7^{*}(1.7)$ & $0.32^{\dagger}(0.13)$ \\
From CRE model with sample selection adjustment & $5.3^{*}(1.7)$ & $0.28^{\dagger}(0.13)$ \\
From FE model & $0.3(1.5)$ & $0.06(0.10)$ \\
Raw difference, infrequent consultation vs. none & $1.5(1.7)$ & $0.14(0.12)$ \\
Within-district difference, infrequent consultation vs. none & $1.4(1.6)$ & $0.12(0.12)$ \\
From CRE model with sample selection adjustment & & \\
From FE model & & \\
\hline
\end{tabular}

Standard errors are in parentheses.

${ }^{*} p<0.05,{ }^{\dagger} p<0.005$

that did not, were the first measures in their respective districts; $\chi^{2}=1.8 ; 1$ degree of freedom [d.f.]; $p=0.18$ ). We found evidence that districts in our sample were less likely to promise frequent direct consultation after their first parcel tax measure (59 percent of measures that promised frequent direct consultation, compared with 42 percent of the measures that did not, were the first tax measures in their respective districts; $\chi^{2}=9.0 ; 1$ d.f.; $\left.p<0.005\right)$. We tested whether this temporal sequencing might affect our inferences by fitting a series of supplemental models equivalent to the models we report in Tables 1 and 2 but with an additional dummy variable in vector $X$ that we set equal to one if a measure was the first parcel tax measure proposed in its respective district and set equal to zero otherwise. The resulting estimates of the effects of consultation on the affirmative vote share were within 0.3 percentage points, and the estimates of the effects of consultation on the probability of passage were within 1 percentage point, of the estimates reported in Tables 1 and 2. We report these sensitivity analyses in the online supplement; they left our quantitative findings almost unchanged from the models reported in Tables 1 and 2.

Regression tables for the analyses reported in Tables 1 and 2, including the within-district coefficients of other policy design features and contextual variables, are also reported in the online supplement. For the most part, the coefficients of the covariates had the hypothesized signs. The within-district $R^{2}$ statistics were 0.38 for both analyses of the affirmative vote share and 0.28 and 0.29 for the CRE and FE analyses of measure passage, respectively.

\section{Concluding Discussion}

Voters in California school districts were more willing to support increased funding for public schools when proposed parcel tax increases gave them additional opportunities to trade taxation for consultation. Our analyses provide evidence that both direct and indirect forms of consultation coincide with increases in voters' willingness to approve tax increases. The promise of repeated direct consultation, or 
the future renewal of a tax by popular vote, correlates with a greater share of votes and a higher probability of passage. Our models suggest that voters responded positively to promises of citizen oversight boards as well: The probability of passage and the percentage of affirmative votes were higher when ballots included an oversight guarantee.

These findings provide evidence that the fiscal theory of democratization may have application to changing political institutions even within already long-established democracies. The exchange of consultation for taxation is not limited to protodemocratic parliaments in authoritarian regimes. Nor are taxpayers' demands for voice and accountability exhausted by constitutional guarantees of equal suffrage, representative legislatures, and the occasional referendum. Even where such institutional guarantees already exist, citizens may want guarantees of more voice in fiscal decision-making whenever more resources are demanded of them. The present findings also suggest that citizen demands for consultation may be satisfied by a variety of institutional forms, ranging from an appointed citizen committee to a direct plebiscite on fiscal decision-making.

Our findings may be of particular use for public school districts. To be sure, California's school finance system is unusual, and our sample is likely to be unrepresentative even of all California school districts. It would be a mistake to assume that every school tax proposal would be 31 percent more likely to become law if it was coupled with provision for a citizens' advisory committee. It seems most plausible to suppose that we observe a difference this large in the present sample because such provisions were put forward precisely where they would make the largest difference. But our findings may be taken to support the general conclusion that measures promising citizen consultation can win the support of some voters for increased school taxes, particularly voters on the margin, who otherwise might be reluctant to pay more for public education. When public schools struggle for resources, it may be useful to consider whether a bargain may be struck that would trade increased taxation for increased citizen voice.

\section{References}

Baskaran, Thushyanthan, and Arne Bigsten. 2013. "Fiscal Capacity and the Quality of Government in Sub-Saharan Africa." World Development 45:92-103. https : //doi .org/ 10.1016/j . worlddev.2012.09.018.

Bates, Robert H., and Da-Hsiang Donald Lien. 1985. "A Note on Taxation, Development, and Representative Government." Politics and Society 14:53-70. https ://doi .org/10.1177/ 003232928501400102.

Bell, Andrew, and Kelvyn Jones. 2015. “Explaining Fixed Effects: Random Effects Modeling of Time-Series Cross-sectional and Panel Data." Political Science Research and Methods 3:133-53. https://doi.org/10.1017/psrm.2014.7.

Benjamin, Daniel J., James O. Berger, Magnus Johannesson, Brian A. Nosek, E. J. Wagenmakers, Richard Berk, Kenneth A. Bollen, Björn Brembs, Lawrence Brown, Colin Camerer, David Cesarini, Christopher D. Chambers, Merlise Clyde, Thomas D. Cook, Paul De Boeck, Zoltan Dienes, Anna Dreber, Kenny Easwaran, Charles Efferson, Ernst Fehr, Fiona Fidler, Andy P. Field, Malcolm Forster, Edward I. George, Richard Gonzalez, Steven 
Goodman, Edwin Green, Donald P. Green, Anthony G. Greenwald, Jarrod D. Hadfield, Larry V. Hedges, Leonhard Held, Teck Hua Ho, Herbert Hoijtink, Daniel J. Hruschka, Kosuke Imai, Guido Imbens, John P. A. Ioannidis, Minjeong Jeon, James Holland Jones, Michael Kirchler, David Laibson, John List, Roderick Little, Arthur Lupia, Edouard Machery, Scott E. Maxwell, Michael McCarthy, Don A. Moore, Stephen L. Morgan, Marcus Munafó, Shinichi Nakagawa, Brendan Nyhan, Timothy H. Parker, Luis Pericchi, Marco Perugini, Jeff Rouder, Judith Rousseau, Victoria Savalei, Felix D. Schönbrodt, Thomas Sellke, Betsy Sinclair, Dustin Tingley, Trisha Van Zandt, Simine Vazire, Duncan J. Watts, Christopher Winship, Robert L. Wolpert, Yu Xie, Cristobal Young, Jonathan Zinman, and Valen E. Johnson. 2017. "Redefine Statistical Significance." Nature Human Behavior 2:6-10. https://doi.org/10.1038/s41562-017-0189-z.

Boucoyannis, Deborah. 2015. "No Taxation of Elites, No Representation: State Capacity and the Origins of Representation." Politics and Society 43:303-32. https : //doi .org/10. $1177 / 0032329215584765$.

Fairbrother, Malcolm. 2014. "Two Multilevel Modeling Techniques for Analyzing Comparative Longitudinal Survey Datasets." Political Science Research and Methods 2:119-40. https://doi.org/10.1017/psrm.2013.24.

Gur, Nurullah. 2014. “Taxation and Democracy: An Instrumental Variable Approach." Applied Economics Letters 21:763-6. https://doi .org/10 .1080/13504851 .2014.889793.

Jackson, C. Kirabo, Rucker C. Johnson, and Claudia Persico. 2016. “The Effects of School Spending on Educational and Economic Outcomes: Evidence from School Finance Reforms." Quarterly Journal of Economics 131:157-218. https://doi.org/10.1093/qje/ qjv036.

Ladd, Helen F., and Julie Boatwright Wilson. 1983. "Who Supports Tax Limitations: Evidence from Massachusetts' Proposition 2 1/2." Journal of Policy Analysis and Management 2:25679. https://doi.org/10.2307/3323286.

Lafortune, Julien, Jess Rothstein, and Diane Whitmore Schanzenbach. 2018. "School Finance Reform and the Distribution of Student Achievement." American Economic Journal: Applied Economics 10:1-26. https://doi.org/10.1257/app. 20160567.

Martin, Isaac William. 2015. “The Fiscal Sociology of Public Consultation.” Pp. 102-24 in Democratizing Inequalities, edited by C. Lee, M. McQuarrie, and E. Walker. New York, NY: New York University Press. https ://doi .org/10.18574/nyu/9781479847273.003. 0006.

Martin, Isaac William, Jane Lilly Lopez, and Lauren Olsen. 2017. “California Local Tax Ballot Measures." University of Cincinnati Libraries Digital Collections and Repositories. https://library.ucsd.edu/dc/collection/bb95934924.

Martin, Isaac William, Jane Lilly López, and Lauren Olsen. 2018. "Policy Design and the Politics of City Revenue: Evidence from California Municipal Ballot Measures." Urban Affairs Review, first published on January 22, 2018, as doi .org/10.1177/1078087417752474.

Møller, Jørgen. 2017. "The Birth of Representative Institutions: The Case of the Crown of Aragon." Social Science History 41:175-200. https ://doi .org/10.1017/ssh . 2017.6.

Mundlak, Yari. 1978. "On the Pooling of Time Series and Cross Section Data." Econometrica 46:69-85. https://doi.org/10.2307/1913646.

O'Brien, Rourke L. 2017. "Redistribution and the New Fiscal Sociology: Race and the Progressivity of State and Local Taxes." American Journal of Sociology 122:1015-49. https : //doi.org/10.1086/690118. 
Owens, Ann. 2018. "Income Segregation between School Districts and Inequality in Students' Achievement." Sociology of Education 91:1-27. https://doi.org/10.1177/ 0038040717741180.

Paler, Laura. 2013. "Keeping the Public Purse: An Experiment with Windfalls, Taxes, and the Incentives to Restrain Government." American Political Science Review 107:706-25. https://doi .org/10.1017/S0003055413000415.

Pearson, Elizabeth. 2014. "Saying Yes to Taxes: The Politics of Tax Reform Campaigns in Three Northwestern States, 1965-1973." American Journal of Sociology 119:1279-323. https://doi.org/10.1086/675386.

Plutzer, Eric, and Michael Berkman. 2005. "The Graying of America and Support for Funding the Nation's Schools." Public Opinion Quarterly 69:66-86. https://doi .org/10.1093/ poq/nfi010.

Ross, Michael L. 2004. “Does Taxation Lead to Representation?" British Journal of Political Science 34:229-49. https : //doi . org/10.1017/S0007123404000031.

Ross, Michael L. 2012. The Oil Curse: How Petroleum Wealth Shapes the Development of Nations. Princeton, NJ: Princeton University Press.

Schumpeter, Joseph. [1918] 1991. "The Crisis of the Tax State." Pp. 99-140 in The Economics and Sociology of Capitalism, edited by R. Swedberg. Princeton, NJ: Princeton University Press.

Scott, Dale. 2013. Win Win: An Insider's Guide to School Bonds. San Francisco, CA: DS\&C Publishing.

Sears, David O., and Jack Citrin. 1985. Tax Revolt: Something for Nothing in California. Cambridge, MA: Harvard University Press.

Semykina, Anastasia, and Jeffrey M. Wooldridge. 2010. “Estimating Panel Data Models in the Presence of Endogeneity and Selection." Journal of Econometrics 157:375-80. https : //doi.org/10.1016/j.jeconom.2010.03.039.

Stolzenberg, Ross M., and Daniel A. Relles. 1990. “Theory Testing in a World of Constrained Research Design: The Significance of Heckman's Censored Sampling Bias Correction for Nonexperimental Research." Sociological Methods and Research 18:395-415. https : //doi.org/10.1177/0049124190018004001.

Tedin, Kent L., Richard E. Matland, and Gregory R. Weiher. 2001. “Age, Race, Self-interest, and Financing Public Schools through Referenda." Journal of Politics 63:270-94. https : //doi.org/10.1111/0022-3816.00068.

Tilly, Charles. 2009. "Extraction and Democracy." Pp. 173-82 in The New Fiscal Sociology: Comparative and Historical Approaches to Taxation, edited by I. W. Martin, A. K. Mehrotra, and M. Prasad. Cambridge, UK: Cambridge University Press. https://doi .org/10. 1017/CB09780511627071.011.

Wooldridge, Jeffrey. 1995. "Selection Correction for Panel Models under Conditional Mean Independence Assumptions." Journal of Econometrics 68:115-32. https ://doi .org/10. 1016/0304-4076 (94)01645-G.

Wooldridge, Jeffrey. 2002. Econometric Analysis of Cross-section and Panel Data. Cambridge, MA: The MIT Press. 
Acknowledgments: This research was supported by the Spencer Foundation (award 201800030) and the National Science Foundation (award 1421993). The authors gratefully acknowledge the research assistance of Jane Lilly López and Lauren Olsen; the generosity of Rod Kiewiet, who shared documents from his own collection of school district parcel tax measures; and the constructive feedback of colleagues at the 2017 Meetings of the Sociology of Education Association.

Isaac William Martin: Department of Sociology, University of California, San Diego. E-mail: iwmartin@ucsd.edu.

Jennifer M. Nations: Scholars Strategy Network. E-mail: jnations@ucsd.edu. 